\title{
Physicochemical properties of skim milk powders prepared with the addition of mineral chelators
}

\author{
V. Sikand, ${ }^{*}$ P. S. Tong, ${ }^{* 1}$ Sean Vink, ${ }^{*}$ and Soma Roy† \\ *Dairy Products Technology Center, and \\ †Statistics Department, California Polytechnic State University, San Luis Obispo 93407
}

\section{ABSTRACT}

The objective of this study was to determine the effect of mineral chelator addition during skim milk powder (SMP) manufacture on the solubility, turbidity, soluble protein, and heat stability (HS). Three chelators (sodium citrate dihydrate, sodium polyphosphate, and disodium EDTA) at 3 different concentrations (5, 15 , and $25 \mathrm{mM}$ ) were added to skim milk concentrate (30\% total solids), and the $\mathrm{pH}$ was adjusted to 6.65 before spray drying to produce SMP. Spray-dried SMP samples were tested for solubility index (SI). Additionally, samples were reconstituted to contain $9 \%$ total solids, adjusted to $\mathrm{pH} 7.0$, and tested for turbidity, protein content from supernatants of ultracentrifuged samples, and HS. Lower SI values were observed for samples treated with $5 \mathrm{mM}$ disodium EDTA and sodium polyphosphate than control samples or samples with $5 \mathrm{~m} M$ sodium citrate dihydrate. Furthermore, lower SI values were observed with an increased level of chelating agents regardless of chelator type. A decreased turbidity value was found with increasing levels of mineral chelating salt treatment. Low turbidity with increasing levels of added chelators may be associated with the dissociation of caseins from micelles. Furthermore, higher protein content was observed in supernatants of ultracentrifuged samples treated with increased level of chelators as compared with the control sample. Higher HS was observed in samples treated with $5 \mathrm{mM}$ compared with samples treated with $25 \mathrm{~m} M$ mineral chelator. The results suggest improved solubility and HS upon addition of mineral chelators to SMP during its manufacture.

Key words: skim milk powder, chelators, solubility, turbidity, heat stability

Received August 11, 2015.

Accepted January 7, 2016.

${ }^{1}$ Corresponding author: ptong@calpoly.edu

\section{INTRODUCTION}

The functionality of skim milk powder (SMP) can be modified by tailoring milk composition and processing techniques. Proteins are responsible for playing a significant role in functional properties. Milk consists of 2 major proteins: casein and whey. Casein proteins form a stable complex with inorganic calcium phosphate and exist in the form of micelles (Schmidt, 1982) and can tolerate severe processing conditions.

Several factors are known to dissociate casein micelles such as pressure (Altuner et al., 2006), alkalization (Vaia et al., 2006), salt such as $\mathrm{NaCl}$ or $\mathrm{KCl}$ (Sikand et al., 2013), acidification (Famelart et al., 1999), and mineral chelating salts (Griffin et al., 1988; Ward et al., 1997; Udabage et al., 2000; de Kort et al., 2012). The applications of these factors to the protein solutions possibly may cause several changes in the casein micelle structure by disrupting ionic, hydrogen, and hydrophobic interactions (Morild, 1981). As a result, functional properties can be manipulated.

Chelators form a soluble complex with metal and alkaline earth ions. Addition of chelators to milk has been known to affect the structure of casein micelles by influencing distribution of calcium and phosphate in the colloidal and soluble phase (Udabage et al., 2000). Furthermore, simultaneous release of caseins from casein micelles (Lin et al., 1972), and reduced light-scattering capabilities (Munyua and Larsson-Raznikiewicz, 1980; Pitkowski et al., 2008) have been reported. These structural changes affect many functional properties such as solubility (Schuck et al., 2002), turbidity, and heat stability (HS; Mohammad and Fox, 1983; de Kort et al., 2012).

Schuck et al. (2002) reported that mineral salts play a significant role in the water transfer during spray drying of native micellar casein. Furthermore, these authors emphasized that the quality of native phosphocaseinate suspension depends on mode/time of incorporation of mineral salt. For example, the addition of mineral salt before spray drying results in de-structuring of casein micelles. Therefore, the mode of incorporation of mineral salt addition (i.e., before, during, or after spray 
drying of milk powder) imparts different characteristics to the powder.

Mineral salt addition to milk products has been reported to improve the HS. Mineral salts such as citrate, EDTA, and oxalate have been reported to reduce $\mathrm{Ca}^{+2}$ in the milk, decrease the colloidal calcium phosphate, and enhance the HS of milk (Mohammad and Fox, 1983; Augustin and Clarke, 1990). de Kort et al. (2012) reported a range of effects on HS could be observed depending upon the type and concentration of mineral chelator. For example, disodium uridine monophosphate, a weak chelator, gave marked increase in HS compared with stronger chelators such as trisodium citrate and disodium hydrogen phosphate, which gave lower HS. The differences in heat stabilities were attributed to calcium ion activity and state of the micellar structure. Additionally, these authors stated that a high concentration of chelators may chelate calcium to such an extent that casein micelle integrity is disrupted. Thus, a high concentration of chelators caused casein micelle disruption, which can affect negatively the HS of milk (de Kort et al., 2012).

No single comprehensive study includes the effect of adding a range of chelators followed by $\mathrm{pH}$ adjustment before spray drying on solubility, turbidity, soluble protein, and HS. Because the present authors believe that the processing treatments may affect stability of milk, the current project aims to compare and understand the effect of the addition of chelator before spray drying of skim milk concentrate and its effects on the other functional properties. Three chelators [sodium citrate dihydrate (SCD), sodium polyphosphate (SPP), and disodium EDTA (DSE)] were selected. The objective of this study was to determine the effects of adding mineral chelators on the functional properties such as solubility, turbidity, soluble protein, and HS of SMP samples. This study would help to manipulate chelator concentration for end user applications in SMP-based products.

\section{MATERIALS AND METHODS}

\section{Manufacturing of SMP Samples}

The SMP powder samples were manufactured at Dairy Products Technology Center (San Luis Obispo, CA). All chemicals used were reagent grade. Commercial low heat SMP from the same lot was reconstituted to $30 \%$ TS concentrates. The required amount of SMP was blended with prewarmed $\left(43^{\circ} \mathrm{C}\right)$ deionized water using a high shear mixer. Mixing continued for $30 \mathrm{~min}$ where after the concentrate was cooled to $4^{\circ} \mathrm{C}$ and allowed to fully hydrate for $48 \mathrm{~h}$ before use. On the day of spray drying, 9 to $11 \mathrm{~kg}$ (20 to $25 \mathrm{lb}$ ) batches of concentrate were warmed to $21^{\circ} \mathrm{C}$ and the required amount (e.g., $0.19,0.33$, and $0.15 \%$ to make $5 \mathrm{mM}$ ) of DSE, SPP, or SCD was added using the Silverson mixer at $50 \%$ power followed by $\mathrm{pH}$ adjustment to 6.65 . Spray drying was conducted using a Niro FilterLab Spray Dryer (Hudson, WI). Inlet temperature was $208.7^{\circ} \mathrm{C}$. Outlet air temperature was $82^{\circ} \mathrm{C}$. One control and 3 powders with 3 chelating salts (DSE, SPP, and SCD) and 3 levels of concentration $(5,15$, and $25 \mathrm{mM})$ were produced. Figure 1 shows the schematic diagram used in this study for manufacturing of skim milk powder. The chelated samples were named according to type and chelator concentration; for example, when SCD was used at the 5,15 , or $25 \mathrm{~m} M$ level, powder and reconstituted samples were referred to as SCD5, SCD15, and SCD25, respectively. Similar naming conventions were used for DSE (DSE5, DSE15, and DSE25) and SPP (SPP5, SPP15, and SPP25) samples.

\section{Solubility Index}

Solubility index (SI) was measured by the ADPI (1990) method. In this method, $10 \mathrm{~g}$ of SMP powder was mixed in a mixer with $100 \mathrm{~mL}$ of water. Three drops of antifoam B solution (Sigma, St. Louis, MO) were added and mixed at speed \#1 (model 51BL31, Waring commercial blender, Torrington, CT) for $90 \mathrm{~s}$. The mixed sample was kept in a beaker for 5 min. Fifty milliliters of the reconstituted milk sample was poured and centrifuged $\left(163 \times \mathrm{g}, 5 \mathrm{~min}, 24^{\circ} \mathrm{C}\right)$ in a conical centrifuge tube. The top supernatant was decanted, and tube was filled with water and centrifuged again. This process was repeated 3 or 4 times to read the sedimentation level clearly. Analyses were performed in duplicate.

\section{Preparation of Reconstituted Milk from SMP Samples}

Ten types of SMP powder samples from 2 different trials were reconstituted in random order to contain $9 \%$ TS content. These samples were stirred for $4 \mathrm{~h}$ at room temperature $\left(21^{\circ} \mathrm{C}\right)$. After $4 \mathrm{~h}$ of stirring at $900 \mathrm{rpm}$ with a laboratory stirrer (R010 Power, IKA Works, Wilmington, $\mathrm{NC}$ ), $\mathrm{pH}$ of samples was recorded and was in the range of 6.9 to 7.0. Therefore, $\mathrm{pH}$ of all the samples was adjusted to 7.0 with $0.1 \mathrm{~N} \mathrm{NaOH}$ or $0.1 \mathrm{~N}$ $\mathrm{HCl}$ and samples were kept in a refrigerator overnight and brought to room temperature $\left(21 \pm 2^{\circ} \mathrm{C}\right)$ the next day. The $\mathrm{pH}$ of all the samples was measured again. These prepared samples were analyzed using different tests described below.

Turbidity. The turbidity of all the reconstituted SMP samples (9\% TS) was measured by using a nephelometer (Micro 1000 IR, Fort Myers, FL). These 
reconstituted samples were diluted in water (1:50). Furthermore, samples were equilibrated at room temperature $\left(21 \pm 2^{\circ} \mathrm{C}\right)$ for $2 \mathrm{~h}$ before measuring turbidity. Turbidity measurements are reported in nephelometric turbidity units.

Heat Stability. Heat stability of reconstituted SMP samples (9\% TS) was measured by using an oil bath method (Davies and White, 1966). Heat stability was determined by measuring heat coagulation time (HCT) with a few modifications. Tubes $(100 \mathrm{~mm} \times 13 \mathrm{~mm})$ containing $2.0 \mathrm{~mL}$ of samples were fitted in a rocker and immersed in an oil bath set at $140^{\circ} \mathrm{C}$. The $\mathrm{HCT}$ measured the time recorded when first coagulation of samples was visible.

\section{Soluble Protein}

Reconstituted samples were ultracentrifuged at $100,000 \times g$ for $1 \mathrm{~h}$ at $21^{\circ} \mathrm{C}$ using a SW50.1 rotor (Beckman Coulter, Fullerton, CA). A firm pellet and a liquid supernatant were formed upon centrifugation. The supernatant was analyzed for total nitrogen measurement by Rapid N Cube (Elementar Analysensysteme GmbH, Hanau, Germany) according to the Dumas combustion method.

\section{SDS-PAGE}

A qualitative protein distribution analysis in the reconstituted samples and their respective ultracentrifuged samples was done by SDS-PAGE (15\%) using a Mini-Protean cell electrophoresis system (Bio-Rad Laboratories, Hercules, CA) per the Laemmli (1970) method. The reconstituted SMP and ultracentrifuged samples were diluted to contain $2 \mathrm{mg} \cdot \mathrm{mL}^{-1}$ protein content. Furthermore, these samples were mixed with a sample buffer in a 1:1 dilution under nonreducing conditions. Gels were run at 110 V. Gels were stained with Coomassie R-250 for 8 to $12 \mathrm{~h}$. The gels were destained the following day.

\section{Statistical Analysis}

Data were analyzed using Fit Model in JMP Pro 9.0.2 (2010, SAS Institute Inc., Cary, NC). A separate one-way ANOVA was run with the factor being the combination of chelator type and concentration (including the control group), and the response was set to be one of the following on each of the separate runs: SI, turbidity, soluble protein, and HS. All of the experiments were performed in duplicate.

\section{RESULTS AND DISCUSSION}

\section{Solubility Index}

The SI results show that all the samples are very soluble as the level of sedimentation was less than 0.5 $\mathrm{mL}$. However, we observed an overall decreasing trend in the sedimentation with increasing level of chelating salt. The effect was more pronounced with increased levels of salt from 5 to $15 \mathrm{~m} M$ or 5 to $25 \mathrm{~m} M$ in samples

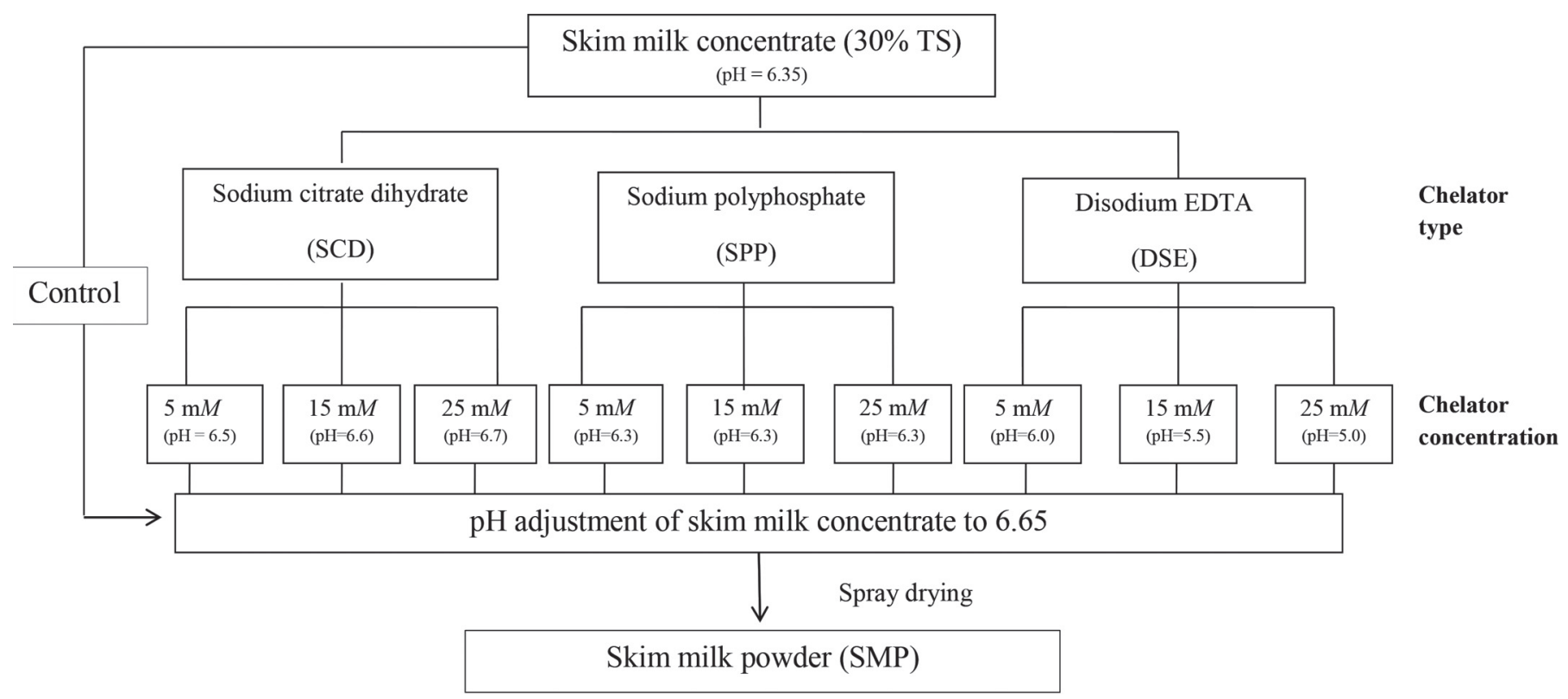

Figure 1. Schematic of manufacturing skim milk powder treated with chelators. 
Table 1. Solubility index (SI) measurement of reconstituted skim milk powder control (without any treatment), and samples treated with chelators and $\mathrm{pH}$ adjusted to 7.0 values $(\mathrm{n}=2)^{1}$

\begin{tabular}{lc}
\hline Sample type & Mean SI \\
\hline Control & $0.290^{\mathrm{a}}$ \\
SCD5 & $0.290^{\mathrm{a}}$ \\
SPP5 & $0.175^{\mathrm{b}}$ \\
DSE5 & $0.100^{\mathrm{c}}$ \\
SCD15 & $0.090^{\mathrm{c}}$ \\
SPP15 & $0.075^{\mathrm{c}}$ \\
DSE15 & $0.070^{\mathrm{c}}$ \\
SCD25 & $0.075^{\mathrm{c}}$ \\
SPP25 & $0.060^{\mathrm{c}}$ \\
DSE25 & $0.050^{\mathrm{c}}$ \\
P-value & $<0.0001$ \\
SE & 0.009 \\
HSD & 0.048
\end{tabular}

$\overline{{ }^{a-c} \text { Letters indicate differences by Tukey's HSD procedure using } \alpha=}$ 0.01 .

${ }^{1} \mathrm{SE}=$ standard error for the mean of each treatment group; HSD $=$ smallest difference between means of 2 groups that is statistically significant $(\alpha=0.01)$. When sodium citrate dihydrate was used at the 5,15 , or $25 \mathrm{~m} M$ level, powder and reconstituted samples are referred to as SCD5, SCD15, and SCD25, respectively. Similar naming conventions are used for disodium EDTA (DSE5, DSE15, and DSE25) and sodium polyphosphate (SPP5, SPP15, and SPP25) samples.

chelated with SCD, SPP. Furthermore, it was observed that milk powders with added DSE5 had lower sedimentation, on average, as compared with milk powders with added SCD5, SPP5, or control $(P<0.0001$; Table $1)$. Further, a lower average sedimentation level was observed for 15 and $25 \mathrm{mM}$ chelator concentration compared with $5 \mathrm{~m} M \mathrm{SCD}, 5 \mathrm{~m} M \mathrm{SPP}$, and control $(P<$ 0.0001).

Schuck et al. (2002) reported that depending upon mode of addition of mineral salt such as citrate and phosphate, enhanced rehydration of native phosphocaseinate dairy powders was observed. Addition of mineral salt to native micellar casein resulted in modifications in the casein micelle structure due to mineral compositional changes (Famelart et al., 1996). Similarly, improved solubility with changes in the mineral composition were reported by adding salt into MPC80 during its manufacturing (Sikand et al., 2013). Likewise, Gaucher et al. (2007) reported that an addition of an increased level of chelator such as potassium dihydrogen phosphate increased the ionic strength and decreased ion activity coefficient. As a consequence, an increased solubilization of calcium phosphate in the soluble phase resulted in modified protein-protein interaction (Schuck et al., 1999), and hence, improved solubility was observed.

Turbidity Measurement. The turbidity measurement of reconstituted SMP, as determined by nephalometer, is shown in Table 2. The turbidity was measured over a range of 3 concentrations $(5,15$, and 25 $\mathrm{m} M)$. Our results indicate that addition of increasing levels of chelating salts during manufacturing of SMP strongly affects the turbidity of milk solutions. Turbidity values show significantly lower values, on average, in samples treated with increased levels of chelators. The average turbidity values were significantly lower in DSE5 or SPP5 compared with SCD5 or control $(P<$ 0.0001). Thus, these results indicate SCD causes lower casein micelle dissociation as compared with DSE or SPP. At a higher concentration such as 15 and $25 \mathrm{mM}$, the extent of casein micelle dissociation increased with increasing concentrations and was much higher in DSE or SPP as compared with SCD chelator. Similar observations of decreasing turbidity and increasing casein micelle dissociation with increasing level of EDTA and polyphosphate were reported by Griffin et al. (1988) and Pitkowski et al. (2008).

Griffin et al. (1988) reported that the removal of the first fraction of calcium and phosphate at low EDTA concentration does not disrupt casein micelle structure. However, removal of the second fraction of calcium under more stringent conditions results in micellar disintegration. Current turbidity results showed that at 5 $\mathrm{m} M$ concentration, samples exhibited lower turbidity values as compared with control $(P<0.001)$.

Furthermore, drastically reduced turbidity values were observed at higher concentration (15 and $25 \mathrm{mM}$ ). These effects were more pronounced in samples treated with DSE, SPP, and then SCD irrespective of chelator concentration.

Table 2. Turbidity measurement of reconstituted skim milk powder control (without any treatment), and samples treated with chelators and $\mathrm{pH}$ adjusted to $7.0(\mathrm{n}=2)^{1}$

\begin{tabular}{lc}
\hline Sample type & Mean turbidity \\
\hline Control & $139.000^{\mathrm{a}}$ \\
SCD5 & $123.000^{\mathrm{b}}$ \\
SPP5 & $102.080^{\mathrm{c}}$ \\
DSE5 & $95.415^{\mathrm{c}}$ \\
SCD15 & $48.500^{\mathrm{d}}$ \\
SPP15 & $39.065^{\mathrm{de}}$ \\
DSE15 & $36.740^{\mathrm{de}}$ \\
SCD25 & $33.500^{\mathrm{e}}$ \\
SPP25 & $5.090^{\mathrm{f}}$ \\
DSE25 & $4.080^{\mathrm{f}}$ \\
P-value & $<0.0001$ \\
SE & 1.804 \\
HSD & 9.203 \\
\hline
\end{tabular}

$\overline{\mathrm{a}-\mathrm{f}}$ Letters indicate differences by Tukey's HSD procedure using $\alpha=$ 0.01 .

${ }^{1} \mathrm{SE}=$ standard error for the mean of each treatment group; HSD $=$ smallest difference between means of 2 groups that is statistically significant $(\alpha=0.01)$. When sodium citrate dihydrate was used at the 5,15 , or $25 \mathrm{~m} M$ level, powder and reconstituted samples are referred to as SCD5, SCD15, and SCD25, respectively. Similar naming conventions are used for disodium EDTA (DSE5, DSE15, and DSE25) and sodium polyphosphate (SPP5, SPP15, and SPP25) samples. 
Table 3. Heat coagulation time (HCT) measurement of reconstituted skim milk powder control (without any treatment), and samples treated with chelators and $\mathrm{pH}$ adjusted to $7.0(\mathrm{n}=2)^{1}$

\begin{tabular}{lc}
\hline Sample type & Mean HCT (min) \\
\hline Control & $8.750^{\mathrm{e}}$ \\
SCD5 & $29.500^{\mathrm{b}}$ \\
SPP5 & $16.500^{\mathrm{d}}$ \\
DSE5 & $34.500^{\mathrm{a}}$ \\
SCD15 & $5.750^{\mathrm{ef}}$ \\
SPP15 & $21.705^{\mathrm{c}}$ \\
DSE15 & $6.710^{\mathrm{ef}}$ \\
SCD25 & $4.500^{\mathrm{ef}}$ \\
SPP25 & $2.200^{\mathrm{f}}$ \\
DSE25 & $2.760^{\mathrm{f}}$ \\
P-value & $<0.0001$ \\
SE & 0.684 \\
HSD & 3.491 \\
\hline
\end{tabular}

${ }^{\mathrm{a}-\mathrm{f}}$ Letters indicate differences by Tukey's HSD procedure using $\alpha=$ 0.01 .

${ }^{1} \mathrm{SE}=$ standard error for the mean of each treatment group; HSD $=$ smallest difference between means of 2 groups that is statistically significant $(\alpha=0.01)$. When sodium citrate dihydrate was used at the 5,15 , or $25 \mathrm{~m} M$ level, powder and reconstituted samples are referred to as SCD5, SCD15, and SCD25, respectively. Similar naming conventions are used for disodium EDTA (DSE5, DSE15, and DSE25) and sodium polyphosphate (SPP5, SPP15, and SPP25) samples.

Heat Stability. The HCT measurement of reconstituted SMP as determined by oil bath method is shown in Table 3. A HS experiment showed that reconstituted samples (pH 7.0) such as DSE5 and SCD5 showed higher HS ( $\geq 30 \mathrm{~min})$ as compared with the SPP5 (17 min) and control samples (9 min). However, SPP15 samples showed significantly higher HS (22 min), on average, than SCD15 or DSE15 samples. Samples showed poor HS ( $<5 \mathrm{~min})$ at $25 \mathrm{~m} M$ concentration level irrespective of chelator type.

Previous studies have reported that calcium chelators enhanced the HS of milk (Mohammad and Fox, 1983) by reducing $\mathrm{Ca}^{2+}$ in the milk, decreasing colloidal calcium phosphate, and possibly decreasing the calciuminduced aggregation of protein (Augustin and Clarke, 1990). Increased HCT value was found to be associated with decreased $\mathrm{Ca}^{2+}$ activity and was attributed to calcium binding capacity of disodium hydrogen phosphate and trisodium citrate. Similarly, Augustin and Clarke (1990) evaluated HS of recombined concentrated milk containing disodium hydrogen phosphate, trisodium citrate, and EDTA and reported structural changes of casein micelles negatively affected HS.

Contrary to low HCT values $(<10 \mathrm{~min})$ reported (Mohammad and Fox, 1983) at pH 7.0 in reconstituted SMP samples treated with mineral chelators such as citrate, our results indicate significant increased HS at low concentration $(5 \mathrm{mM})$. This may be due to additional heat treatment given after chelator addition and before the spray-drying process of SMP. Furthermore, on aver- age, maximum HCT was observed for DSE5 followed by SCD5 and then SPP5. Decreasing HCT values were observed at 15 and $25 \mathrm{mM}$ concentration of chelators. However, higher HCT values were observed in SPP15 as compared with DSE or SCD chelator treatment at similar concentration. At higher chelator concentration $(25 \mathrm{~m} M)$, poor HS may be due to soluble aggregate formation among released casein macromolecules. The translucent samples treated with $25 \mathrm{mM}$ concentration of mineral chelators at $140^{\circ} \mathrm{C}$ turned an opaque color and then flocculated quickly.

\section{Ultracentrifuged Samples from Reconstituted Samples}

The protein content in the supernatant fractions of the reconstituted samples was measured. Table 4 shows the ANOVA results. With an increase in the chelator concentration, an increase in the average soluble protein content was observed. The mean total protein content of DSE25, was higher than SCD25 $(P<0.001)$ and thus, also correlated positively with turbidity results. These results showed extent of casein micelle dissociation with release of protein content was higher in DSE25 concentration of chelators as compared with SCD25 $(P<0.001)$ and SPP25. A similar trend was observed at low concentration $(5$ or $15 \mathrm{mM})$. However, the effects were not as pronounced compared with 25 $\mathrm{m} M$ concentration.

Table 4. Results of ANOVA showing mean protein content (g.100 $\left.\mathrm{g}^{-1}\right)$ for supernatants of ultracentrifuged samples treated with different types and concentration of chelators $(n=2)^{1}$

\begin{tabular}{lc}
\hline Sample type & Mean protein \\
\hline Control & $1.660^{\mathrm{f}}$ \\
SCD5 & $2.040^{\mathrm{e}}$ \\
SPP5 & $2.020^{\mathrm{e}}$ \\
DSE5 & $2.180^{\mathrm{e}}$ \\
SCD15 & $3.015^{\mathrm{d}}$ \\
SPP15 & $3.030^{\mathrm{cd}}$ \\
DSE15 & $3.270^{\mathrm{bc}}$ \\
SCD25 & $3.260^{\mathrm{bc}}$ \\
SPP25 & $3.400^{\mathrm{ab}}$ \\
DSE25 & $3.525^{\mathrm{a}}$ \\
P-value & $<0.0001$ \\
SE & 0.034 \\
HSD & 0.171
\end{tabular}

$\overline{\mathrm{a}-\mathrm{f}}$ Letters indicate differences by Tukey's HSD procedure using $\alpha=$ 0.01 .

${ }^{1} \mathrm{SE}=$ standard error for the mean of each treatment group; HSD = smallest difference between means of two groups that is statistically significant $(\alpha=0.01)$. When sodium citrate dihydrate was used at the 5,15 , or $25 \mathrm{~m} M$ level, powder and reconstituted samples are referred to as SCD5, SCD15, and SCD25, respectively. Similar naming conventions are used for disodium EDTA (DSE5, DSE15, and DSE25) and sodium polyphosphate (SPP5, SPP15, and SPP25) samples. 
Thus, these results suggest that increasing levels of chelators in milk result in increasing soluble protein and decreasing turbidity, which indicates dissociation of casein micelles. de Kort et al. (2012) reported that dissociated casein micelles were more sensitive to calcium induced protein aggregation than intact casein micelles. Furthermore, these authors demonstrated decreasing calcium ion activity and decreasing turbidity with increasing viscosity in reconstituted micellar casein solution containing $9 \%$ protein content with added chelators $\left(0\right.$ to $\left.105 \mathrm{mEq} \cdot \mathrm{L}^{-1}\right)$ such as disodium hydrogen phosphate, sodium hexametaphosphate, phytic acid dodecasodium salt hydrate, and trisodium citrate. Thus, these changes may be responsible for decreased HS at higher chelator concentration (15 and $25 \mathrm{mM}$ ).

Augustin and Clarke (1990) reported that extent of casein micelle dissociation was associated with dissolution of colloidal calcium phosphate from the micelle. Similarly, Lin et al. (1972) reported calcium ion chelation with EDTA resulted in casein micelle dissociation. At low concentration of EDTA, only a small fraction of the micelles was dissociated. Furthermore, these authors reported soluble proteins as $\beta-\mathrm{CN}$ and $\kappa-\mathrm{CN}$, whereas most of the $\alpha-\mathrm{CN}$ was associated with micellar casein complex. A controlled dialysis of casein micelles was conducted against lactose-free simulated milk ultrafiltrate containing EDTA at various concentrations. It should be noted that Lin et al. (1972) performed dialysis at low temperature $\left(5^{\circ} \mathrm{C}\right)$, which is known to dissociate $\beta-\mathrm{CN}$ from casein micelle complex. Those authors attributed initial removal of $\mathrm{Ca}^{2+}$ from casein micelles by addition of a low concentration of EDTA. The current study shows increased protein solubilization especially $\alpha-\mathrm{CN}, \beta-\mathrm{CN}$, and $\mathrm{k}-\mathrm{CN}$ with increased level of SCD, DSE, or SPP chelators treated ultracentrifuged samples (Figure $2 \mathrm{a}$ and $2 \mathrm{~b}$ ). The SDS-PAGE analyses of 10 types of reconstituted milk samples showed differences in the band intensities. Figure $2 \mathrm{~b}$ shows that band intensities of $\alpha-\mathrm{CN}, \beta-\mathrm{CN}$, and $\mathrm{k}-\mathrm{CN}$ protein of the ultracentrifuged supernatants of SMP were higher at $25 \mathrm{mM}$ chelator concentration compared with $5 \mathrm{mM}$ concentration. Our results show that higher concentration of mineral chelators induce solubilization of casein fractions compared with the control sample.

Munyua and Larsson-Raznikiewicz (1980) reported addition of $5 \mathrm{~m} M$ EDTA caused casein micelle dissociation as an increased number of relatively small casein micelles with simultaneous release of monomeric casein in the soluble phase. Further, a decrease in the light scattering was reported. These authors reported release of $\mathrm{Ca}^{2+}$ and without any change in the phosphate at $5 \mathrm{~m} M$ concentration. It was suggested that there are 2 forms of calcium; one form of calcium is responsible for structure and other form leaves the micelle and attributes to light scattering properties. Similar to the above results, current finding show significant difference in the turbidity values at the $5 \mathrm{mM}$ concentration level. It was to be noted that we conducted trials with prior $\mathrm{pH}$ adjustment. Small changes at $5 \mathrm{~m} M$ concentration were observed with respect to color change as compared with the control sample. However, significant differences were observed at 15 and $25 \mathrm{mM}$ concentration, which shows translucent color development.

Samples with an increasing level of chelating salt, a decreasing size of the pellet containing undissociated casein micelle was observed. All the undissociated caseins are precipitated in the form of a pellet while dissociated casein remained in the supernatant. At similar concentration, maximum dissociation was observed in DSE followed by SPP and SCD. Furthermore, irrespective of chelator type, the average protein content in the soluble fraction was significantly higher at $25 \mathrm{mM}$ concentration followed by $15 \mathrm{mM}$ and then $5 \mathrm{~m} M$ concentration as compared with the control sample. Similar observations were made by Gaucher et al. (2007) who demonstrated casein micelle solubilization upon adding potassium phosphate. Further, similar effects were seen by acidification (Famelart et al., 1999), alkalinization (Ahmad et al., 2009), salt addition (Vaia et al., 2006; Sikand et al., 2013), and thus, results suggest considerable modification in the casein micelles (Gaucheron, 2005).

\section{CONCLUSIONS}

The effect of adding chelators to skim milk concentrate before spray drying was investigated to study solubility, turbidity, soluble proteins, and HS of reconstituted skim milk powder. Current study demonstrates that at low chelator concentration of $5 \mathrm{~m} M$, HS can be enhanced even at $\mathrm{pH}$ 7.0. However, at higher concentration of chelator usage, adverse effects were seen on the HS. By carefully manipulating chelator addition, HS can be optimized. Further, addition of chelators improved the solubility of SMP. Thus, chelator treated SMP with improved solubility, HS may form the basis of value-added SMP with enhanced functionality.

\section{ACKNOWLEDGMENTS}

Financial support of this work by the Dairy Research Institute (Rosemont, IL) and California Dairy Research Foundation (Davis, CA) is appreciated. The authors thank Craig Stubler (Cal Poly State University) for technical laboratory analysis support. 


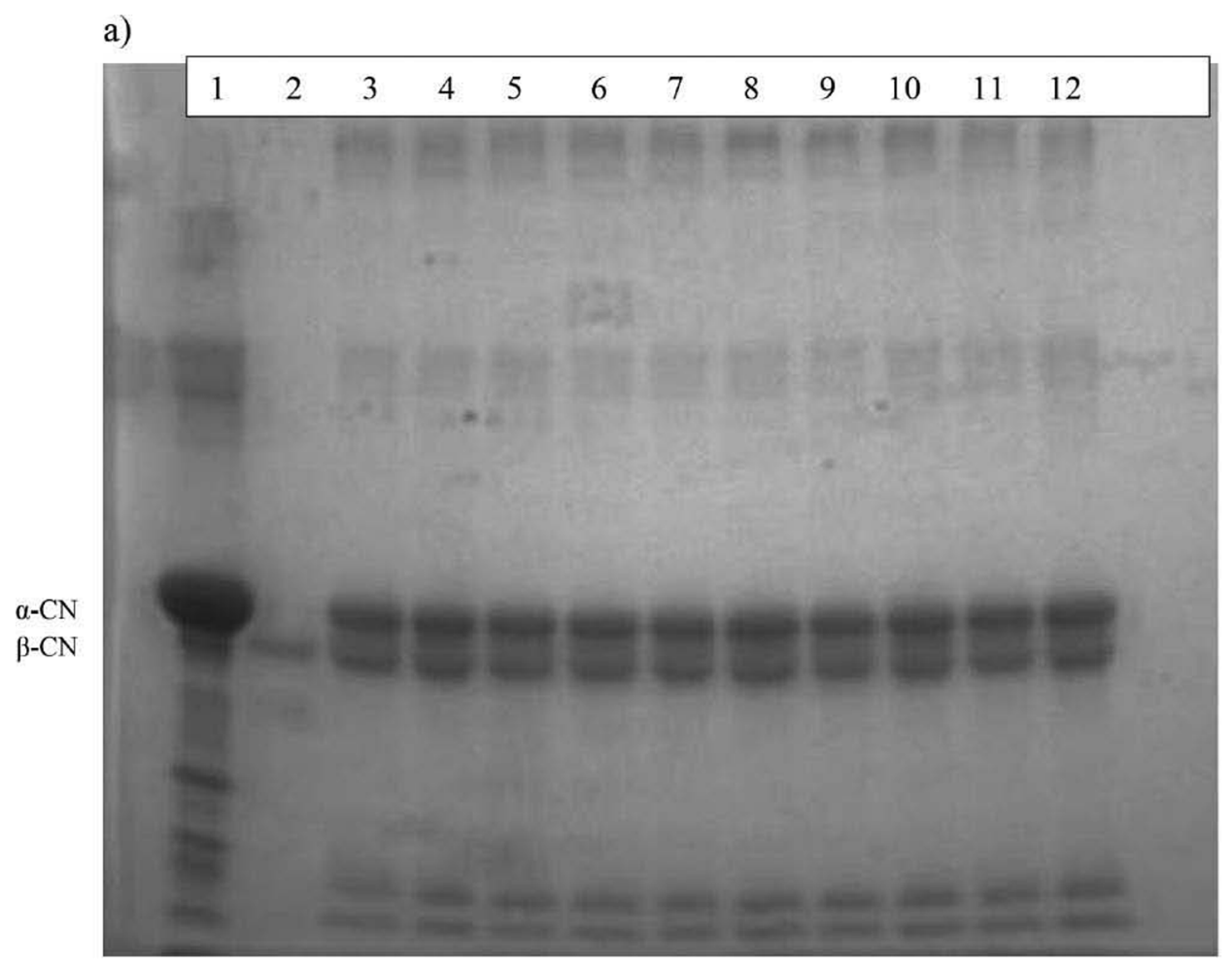

b)

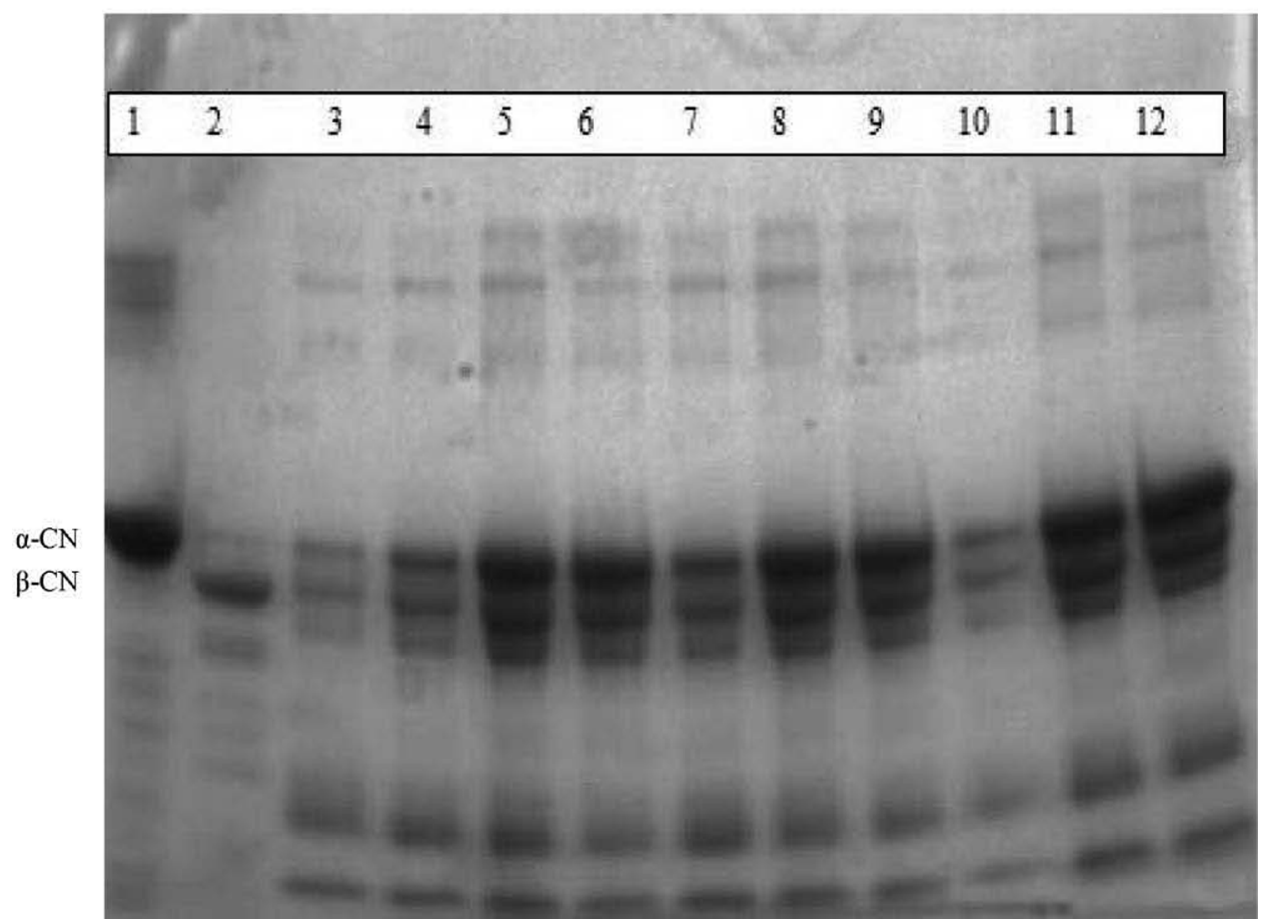

Figure 2. (a) SDS-PAGE of reconstituted skim milk powder (SMP) under nonreduced conditions. Lane $1=\alpha$-casein $(\alpha$-CN) standard; lane $2=\beta$-casein $(\beta-\mathrm{CN})$ standard; lane $3=$ control; lane $4-6=$ reconstituted SMP treated with SCD $(5,15$, and $25 \mathrm{~m} M)$; lane $7-9=$ reconstituted SMP treated with SPP $(5,15$, and $25 \mathrm{mM})$; lane 10-12 = reconstituted SMP treated with DSE (5, 15, and $25 \mathrm{mM})$. (b) SDS-PAGE of ultracentrifuged reconstituted SMP under nonreduced conditions. Lane $1=\alpha$-casein standard; lane $2=\beta$-casein standard; lane $3=$ control; lane $4-6$ $=$ reconstituted SMP treated with SCD $(5,15$, and $25 \mathrm{mM})$; lane 7-9 = reconstituted SMP treated with SPP $(5,15$, and $25 \mathrm{~m} M)$; lane $10-12$ $=$ reconstituted SMP treated with $\mathrm{DSE}(5,15$, and $25 \mathrm{mM})$. SCD $=$ sodium citrate dihydrate; $\mathrm{SPP}=$ sodium polyphosphate; DSE $=$ disodium EDTA. 


\section{REFERENCES}

ADPI. 1990. Standards for grades of dry milks including methods of analysis. ADPI: Bulletin 916 (revised). ADPI, Chicago, IL.

Ahmad, S., M. Piot, F. Rousseau, J. Grongnet, and F. Gaucheron. 2009. Physico-chemical changes in casein micelles of buffalo and cow milks as a function of alkalinisation. Dairy Sci. Technol. 89:387-403.

Altuner, E., H. Alpas, Y. Erdem, and F. Bozoglu. 2006. Effect of high hydrostatic pressure on physicochemical and biochemical properties of milk. Eur. Food Res. Technol. 222:392-396.

Augustin, M.-A., and P. T. Clarke. 1990. Effects of added salts on the heat stability of recombined concentrated milk. J. Dairy Res. $57: 213-226$.

Davies, D. T., and J. C. D. White. 1966. The stability of milk protein to heat: I. Subjective measurement of heat stability of milk. J. Dairy Res. 33:67-81.

de Kort, E., M. Minor, T. Snoeren, T. van Hooijdonk, and E. van der Linden. 2012. Effect of calcium chelators on heat coagulation and heat-induced changes of concentrated micellar casein solutions: The role of calcium-ion activity and micellar integrity. Int. Dairy J. 26:112-119.

Famelart, M., H. F. Lepesant, F. Gaucheron, Y. Le Graet, and P. Schuck. 1996. pH-Induced physicochemical modifications of native phosphocaseinate suspensions: Influence of aqueous phase. Lait 76:445-460.

Famelart, M., Y. Le Graet, and K. Raulot. 1999. Casein micelle dispersions into water, $\mathrm{NaCl}$ and $\mathrm{CaCl}_{2}:$ Physicochemical characteristics of micelles and rennet coagulation. Int. Dairy J. 9:293-297.

Gaucher, I., M. Piot, E. Beaucher, and F. Gaucheron. 2007. Physico-chemical characterization of phosphate-added skim milk. Int Dairy J. 17:1375-1383.

Gaucheron, F. 2005. The minerals of milk. Reprod. Nutr. Dev. 45:473483.

Griffin, M., R. Lyster, and J. Price. 1988. The disaggregation of calcium-depleted casein micelles. Eur. J. Biochem. 174:339-343.

Laemmli, U. 1970. Cleavage of structural proteins during the assembly of the head of bacteriophage T4. Nature 227:680-685.
Lin, S. H. C., S. L. Leong, R. K. Dewan, V. A. Bloomfield, and C. V. Morr. 1972. Effect of calcium ion on the structure of native bovine casein micelles. Biochemistry 11:1818-1821.

Mohammad, K. S., and P. F. Fox. 1983. Influence of some polyvalent organic acids and salts on the colloidal stability of milk. Int. J. Dairy Technol. 36:112-117.

Morild, E. 1981. The theory of pressure effects on enzymes. Adv. Protein Chem. 34:93-166.

Munyua, J., and M. Larsson-Raznikiewicz. 1980. The influence of $\mathrm{Ca}^{2+}$ on the size and light scattering properties of casein micelles. Milchwissenschaft 35:748-749.

Pitkowski, A., T. Nicolai, and D. Durand. 2008. Scattering and turbidity study of the dissociation of casein by calcium chelation. Biomacromolecules 9:369-375.

Schmidt, D. G. 1982. Association of caseins and casein micelle structure. Pages 61-86 in Developments in Dairy Chemistry. Vol. 1. P. Fox, ed. Applied Science Publishers Ltd., London, UK.

Schuck, P., V. Briard, S. Mejean, M. Piot, M. Famelart, and J. Maubois. 1999. Dehydration by desorption and by spray drying of dairy proteins: Influence of the mineral environment. Dry Technol 17:1347-1357.

Schuck, P., A. Davenel, F. Mariette, V. Briard, S. Méjean, and M. Piot. 2002. Rehydration of casein powders: Effects of added mineral salts and salt addition methods on water transfer. Int. Dairy J. 12:51-57.

Sikand, V., P. Tong, and J. Walker. 2013. Effect of adding salt during the diafiltration step of milk protein concentrate powder manufacture on mineral and soluble protein composition. Dairy Sci. Technol. 93:401-413.

Udabage, P., I. R. McKinnon, and M. A. Augustin. 2000. Mineral and casein equilibria in milk: Effects of added salts and calciumchelating agents. J. Dairy Res. 67:361-370.

Vaia, B., M. A. Smiddy, A. L. Kelly, and T. Huppertz. 2006. Solventmediated disruption of bovine casein micelles at alkaline $\mathrm{pH}$. J. Agric. Food Chem. 54:8288-8293.

Ward, B. R., S. J. Goddard, M. A. N. N. Augustin, and I. Mckinnon. 1997. EDTA-induced dissociation of casein micelles and its effect on foaming properties of milk. J. Dairy Res. 64:495-504. 